\title{
Research on Current Running Situations and Measures of Sports Halls for Charging in Colleges
}

\author{
GUAN Duohong ${ }^{1, a}$ \\ ${ }^{1}$ Department of physical education of Panzhihua University Panzhihua 617000, China \\ a39094720@qq.com
}

Keyword: Sports halls, Running management, Current situations

\begin{abstract}
In contemporary society, with China's education level is on the rise, each and every college is well equipped with a comprehensive sports hall. However, in terms of every single college sports hall, a large number of problems which wait to be solved exist among them, such imbalanced distribution, simple running pattern, lack of talents and funds as well as low service quality.

This passage is to analyze and research present running situations of sports halls in colleges through the ways such as documentary methods, interview method and logic analyzing method, pointing out the problems and disadvantages in the process of running and managing of sports halls in colleges and coming up with corresponding measures and suggestions.
\end{abstract}

\section{Introduction.}

Sports halls in colleges are very important hardware facilities in sports education of colleges, which have played a significant role in developing students' capabilities of sports and strengthening students' health qualities.

As a matter of fact, sports halls in colleges are used only for teaching and training and a large amount of extra space is wasted. Therefore, it is a must to transform the current running and managing patterns of sports halls in colleges. According to the present circumstance, it is not influential. The majority of sports halls in colleges have tried to open to the outside after satisfying the requirements of teaching and training. Having investigated and interviewed a number of sports halls in colleges, we are able to draw a conclusion that most of the sports halls in colleges are run and managed in the charge of colleges themselves. Besides, most of the sports halls are still the financial burdens of colleges.

\section{Present running and managing situations of sports halls in colleges. \\ Managing patterns of college sports halls in downtown areas.}

Most of the sports halls in colleges in downtown areas are open to the outside at a special time in the whole year while those in uptown areas are just open at a special time of a single term.

Colleges in downtown areas, due to their traffic advantages, possess a large amount of social resources. That is why they are able to open to the society while meeting the needs of students.

With people's health awareness increasing in the contemporary society, this kind of college sports halls can be run well but hardly concentrate on both running and maintenance. Those college sports halls in uptown areas are deficient in social resources as their service target just involves students and teachers. Thus, they can't be run quite well.

Imbalanced distribution of sports halls.

The majority of college sports halls are state-owned ones, thus, private colleges don't possess comprehensive sports halls as they are devoid of fund. As most of the colleges expand their student recruitment, they set up new campuses on the outskirts of the city. As a result, college sports halls are mostly distributed in uptown areas instead of downtown areas.

\section{Difficulty of controlling opening degree.}

As the main tasks of college sports halls are to satisfy the needs of sports teaching and training, college sports halls are unstable and inconsistent in opening to the outside. If opened completely to the society, colleges' internal needs can't be satisfied. If used only for the inside, financial burdens will be quite heavy. The degree between both sides can't be controlled well. The majority of college 
sports halls are open to the outside only after colleges’ internal requirements are satisfied.

\section{Shortcomings and problems of college sports halls' management. Single functions and unsatisfactory business benefits.}

Sports halls of most of the colleges can allow too many sports programs to begin at the same time due to narrow hall space. Most of the sports halls just open few sports programs such as badminton, table tennis, fitness exercise and basketball with few people being able to enjoy it. Managing staff will be relatively discouraged as a result of bad managing benefits.

Deficiency of managing talents and low quality of hall service.

Few college sports halls own mature managing mechanism and professional managing department and team. At present, managing administrators are generally those logistics staff or sports teachers who take charge of sports halls as a part-time job. The service targeting groups are mostly workers and temporary workers who are not well-educated. Consequently, high-quality service can hardly be provided. Besides, average college sports halls are not equipped with professional sports instructors. Thus, consumers can't be guided in the correct direction, which greatly cuts back on their initiative, passion and enthusiasm. In addition, administrators are devoid of related working experience, professional knowledge and initiative. What's worse, they even work and serve with a greedy thought and are unwilling to take an active part in their duties.

\section{Measures and suggestions.}

\section{Management in multiple ways.}

Most of the college sports halls are invested by both state and school who have spent large amounts of fund on them. And the functions of college sports halls are mainly to satisfy the requirements of teaching and training. After it is well done, sports halls may be opened to the outside so as to earn enough fund to support itself financially. Opening time can be started from any time point except teaching and training time, such as noon, evening, weekend and holiday. A number of programs, such as fitness exercise, pool, chess and cards, can be opened to the outside all day long.

\section{Emphasis on publicity.}

A great many administrators are deficient in managing ability, considering their sports hall good enough and unnecessary to publicize.

In contemporary markets, administrators have to go out and publicize themselves to the society. Only in this way can they survive in such a competitive society. When profile is increased, benefits will be naturally better. In the mean time, training and coordinating of administrators and direct servants must be taken into consideration so that service may be regulated and service level may be increased. Besides, college sports halls may also consider the possibilities of creating a Package Service System to provide customers comfortable service.

Meanwhile, due to the great significance in people's mind, college sports halls ought to actively create life-long sports and lead customers to a healthy life concept. In addition, administrator should also make every effort to build a healthy and optimistic cultural atmosphere so as to let customers consume there voluntarily.

Establishment of perfect running mechanism and cultivation of talents.

All-around managing mechanism and financial rules are essential parts for the running and management of a sports hall.

First of all, special stimulating mechanism may be created in order to fully mobilize employees' enthusiasm. Besides, strict examination regulations must be implemented so as to rid the obsolete and keep the excellent.

Present administrators of sports halls are generally those borrowed from logistics department or sports teachers working as a part-time job. The former possess excellent managing capabilities, but not professional sports knowledge and skills. The latter possess related professional sports knowledge and skills, but are devoid of managing capabilities and experience.

Therefore, colleges would better strengthen training for the administrators in terms of expertise 
and skills so as to increase their individual qualities and levels. If necessary, colleges may take into consideration bringing in professional administrators from the outside to set up a enterprise-style management system. What's more, financial right, decision-making power, hiring right and distributing right should be moved to the administrators to some extent and sports halls are able to take market-orientation pattern into account.

\section{More opening to the outside.}

Currently, running and managing ways of college sports halls are too simple, thus, colleges are supposed to expand their opening to the outside with multiple ways and diverse running and managing patterns.

To begin with, take an active part in seeking social investment and advertisement. Secondly, college sports halls must own multiple running ways. For instance, spare a sports court exclusively for customers to exercise; set up VIP system to widely attract more customers to consume; supply professional stuff to customers for renting and purchasing; provide food and drink as well as spa and health care service. In addition to the above ways, college sports halls may also take on various matches and business activities to expand the profile and accumulate related advanced experience. Moreover, some supporting houses may be rented to the outside so as to earn more and more extra fund.

Last but not least, college sports halls are required to put people first, making more efforts on opening time, price and service.

\section{Summary.}

To draw a conclusion from what has been claimed in the above part, functions of college sports halls in China are too simple and can't satisfy the average requirements of customers. As a matter of fact, to consider from another perspective, mature running and managing patterns of college sports halls still haven't taken shape after all they just start.

As far as I am concerned, college sports halls are supposed to firmly adhere themselves to the principle of multiple-way running pattern. Besides, in the process of their running, they must put teaching and training in the prior positions and well handle the relationship between teaching and opening to the outside.

To well run a sports hall, function of media can't be ignored. As a result, effects of advertisement and publication have to be given priority to. Afterwards, it is essential to regulate service, constantly increase service level, strengthen guide and create a healthy and optimistic sports culture.

Most importantly, establishing and improving running and managing mechanism as well as bringing in more professional management talents are indispensible parts of developing a successful college sports hall while adopting multiple ways to expand the business effect and efficiency.

\section{References.}

[1] HanHaijun, Comparison Analysis of Management Patterns in College Sports Halls[J], Academic Paper of Chengdun Sports College, 2002(2).

[2] GuDongmei, Discusses on Professional Management Patterns in College Sports Halls[J]. Academic Paper of Wuhan Sports College, 2005(4).

[3] ZhangTieming, Current Situations and Running Measures of College Sports Halls[J]. Academic Paper of Hebei Sports College, 2002(3).

[4] RenBaoguo, Sports Industry Theory and Development Strategy Research of Average Colleges and Sports Colleges[J], Sports Science, 2004(7): 69-73.

[5] HuoJianxin, Research on Current Running Situation of Comprehensive College Sports Halls in Beijing[J]. Academic Paper of Beijing Sports University, 2007(5). 